\title{
AVALIAÇÃO DA ATIVIDADE MUTAGÊNICA DA TALIDOMIDA PELO TESTE DE AMES
}

\author{
Evaluation of thalidomide mutagenic activity by Ames test \\ Jean L. Santos ${ }^{1 *}$, Eliana A. Varanda ${ }^{2}$, Lídia M. Lima ${ }^{3}$, Chung M. Chin ${ }^{1}$ \\ ${ }^{1}$ Lapdesf - Laboratório de Pesquisa e Desenvolvimento de Fármacos - Universidade Estadual Paulista "Júlio de \\ Mesquita Filho" UNESP Araraquara - Faculdade de Ciências Farmacêuticas - Depto. Fármacos e Medicamentos \\ 2 Universidade Estadual Paulista "Júlio de Mesquita Filho" UNESP Araraquara - Faculdade de Ciências \\ Farmacêuticas - Depto. Ciências Biológicas \\ ${ }^{3}$ LASSBio - Laboratório de Avaliação e Síntese de Substâncias Bioativas - Universidade Federal do Rio de \\ Janeiro - Faculdade de Farmácia
}

*autor para correspondência e-mail: jeanleandrosantos@yahoo.com.br

Recebido em 20/08/2007 - Aceito em 30/11/2007

RESUMO: A reintrodução da talidomida, reconhecidamente teratogênica, como fármaco potencial em uma série de doenças como por exemplo SIDA, câncer, tuberculose, artrite reumatóide, doença de Crohn, mieloma e síndromes mielodisplásicas requer a avaliação do potencial genotóxico para uso em humanos. No presente trabalho avaliamos a capacidade da talidomida em induzir mutação através do teste de AMES em linhagens TA100 e TA102 de Salmonella typhimurium, na presença ou ausência de ativação metabólica. Os resultados mostraram que a talidomida não apresenta potencial mutagênico, entretanto, outros ensaios genotóxicos devem ser realizados a fim de atestar essa observação.

PALAVRAS-CHAVE: talidomida; Salmonella typhimurium ; testes de mutagenicidade.

ABSTRACT: The reintroduce of thalidomide, known as theratogenic drug, potentially useful in several diseases like AIDS, cancer, tuberculosis, arthritis, Crohn disease, mieloma and mielodisplasic syndromes requires genotoxic evaluation for human use. In this work we evaluated the capacity of thalidomide induce mutation using AMES test with TA100 and TA102 strains of Salmonella typhimurium, on presence or absence of metabolic activation. The results showed that thalidomide not presents mutagenic potency, although, another genotoxic tests must be realized for the purpose of testify this observation.

KEYWORDS: thalidomide; Salmonella typhimurium; mutagenicity tests.

\section{INTRODUÇÃO}

A talidomida de nome químico: [( \pm 2-(2,6-dioxo-3-piperidinil)-1H-isoindol-1,3-(2H)-diona]; ou ( \pm )ftalimidoglutarimida (Figura 1), descoberta em 1953 e utilizada como hipnótico e sedativo, foi prescrita como agente anti-náusea principalmente para grávidas que apresentavam mal estar matinal no início da década de 60. Foi apontada como responsável pelo nascimento de milhares de crianças com deformações congênitas, devido ao seu até então desconhecido, efeito teratogênico. Estes efeitos observados levaram a retirada do mercado da talidomida logo após essas observações (PALENCIA et al, 2007; MELCHERT \& LIST, 2007). 


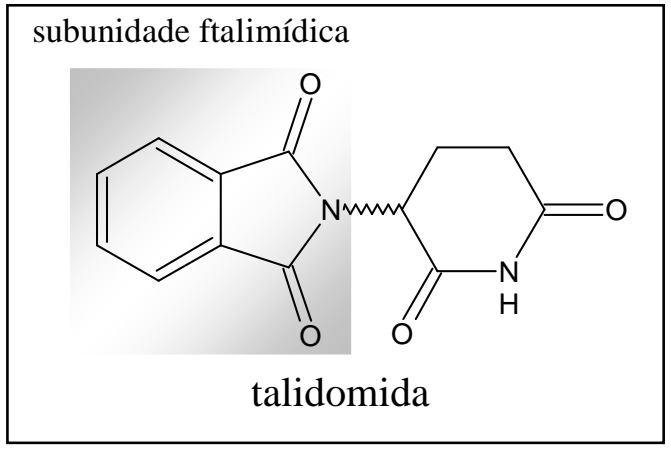

Figura 1: Estrutura química da talidomida.

A despeito desta atividade teratogênica, a talidomida é ainda utilizada em pacientes com hanseníase, e auxilia na redução da dor e do processo inflamatório associado ao leproma. O mecanismo molecular de ação não é ainda completamente elucidado, mas sabe-se que o fármaco auxilia na modulação dos níveis da citocina próinflamatória TNF alfa (fator de necrose tumoral alfa). Estudos da relação entre a estrutura química e a atividade biológica evidenciaram o caráter farmacofórico da subunidade ftalimídica (Figura 1) na inibição da síntese do TNF alfa (LIMA et al, 2001).

Devido à capacidade de modular os níveis de TNF alfa, a talidomida foi ensaiada em doenças como artrite reumatóide e doença de Crohn em que os níveis desta citocina encontram-se elevados. Entretanto, outras aplicações terapêuticas potenciais têm sido relatadas em doenças como câncer, onde o fármaco interfere na angiogênese; AIDS atuando no retardamento da replicação do HIV, e no auxílio da perda de peso de pacientes aidéticos e tuberculosos. Ademais, sua utilização em mieloma múltiplo e síndromes mielodisplásicas motivaram a descoberta da lenalidomida que foi aprovada pelo FDA em dezembro de 2005 (MELCHERT \& LIST, 2007).

Apesar dos efeitos benéficos para o tratamento de várias doenças, o estigma quanto à utilização do fármaco persiste e mais estudos são necessários a fim de entender o potencial genotóxico desta substância. Há controvérsias sobre a capacidade mutagênica deste composto, e freqüentemente a atividade mutagênica tem sido associada à carcinogênese em humanos (ASHBY et al, 1997; MIYACHI et al, 1997). Grande parte dos carcinógenos humanos são também mutagênicos, por isso a avaliação deste fármaco se faz necessária a fim de atestar sua segurança (ZHU et al, 1999).

Outros testes devem ser realizados a fim de avaliar a toxicidade genética de algumas substâncias, como por exemplo, o teste de micronúcleo em medula óssea de roedores in vivo (FAGUNDES et al, 2005). Entretanto, deve-se considerar que o teste de AMES detecta mutações gênicas enquanto o teste do micronúcleo avalia as mutações cromossômicas (UMBUZEIRO et al, 2004).

O objetivo deste trabalho foi avaliar a capacidade mutagênica da talidomida através do teste de AMES nas linhagens TA100 e TA102 de Salmonella typhimurium na presença e na ausência de ativação metabólica.

\section{MATERIAL E MÉTODOS}

\section{Material}

Caldo nutriente Oxoid ํㅡ 2, talidomida (Sigma Aldrich), cloreto de sódio, agar, dimetilsulfóxido (DMSO), biotina, histidina, sulfato de magnésio, ácido cítrico, fosfato de potássio dibásico, fosfato de sódio e amônio, cloreto de magnésio, cloreto de potássio, glicose, NAPD, fosfato de sódio dibásico, fosfato de sódio monobásico, fração S9, Salmonella typhimurium linhagens TA100 e TA102.

\section{Métodos}

Teste de Ames (MARON \& AMES, 1983)

Utilizou-se o método de pré-incubação. As placas foram preparadas da seguinte forma: ao ágar mínimo glicosado esterilizado se adicionou meio VB 50X e solução de glicose $40 \%$ (previamente preparados). Essa mistura foi homogeinizada e distribuída nas placas. Estas foram deixadas em repouso por 48 horas em estufa a $37^{\circ} \mathrm{C}$ para utilização posterior.

As bactérias (linhagens TA100 e TA102) foram inoculadas com auxílio de alça de platina no caldo nutriente estéril e mantidas a $37^{\circ} \mathrm{C}$ sob agitação por 14 horas.

Todos os ensaios foram realizados em triplicata, e em cada tubo foi adicionado $0,1 \mathrm{~mL}$ da cultura de bactérias e as seguintes concentrações de solução de talidomida (solubilizada em DMSO): 0,0309;0,155; 0,774; 
3,87; $19,4 \mu \mathrm{mol} /$ placa. O controle negativo utilizado foi o DMSO, que foi o solvente utilizado para solubilizar a talidomida. Os controles positivos foram compostos conhecidamente mutagênicos e específicos para cada cepa, sendo de azida sódica (1,25 $\mu \mathrm{g} /$ placa) e 2-antramina $(1,25 \mu \mathrm{g} / \mathrm{placa})$ para a linhagem TA 100 na ausência e na presença de ativação metabólica respectivamente. Para a linhagem TA 102 os controles utilizados foram mitomicina $(0,5 \mu \mathrm{g} /$ placa $)$ e de 2-aminofluoreno (1,25 $\mu \mathrm{g} /$ placa) na ausência e na presença de ativação metabólica respectivamente. Os tubos contendo os compostos e a bactéria foram pré-incubados em estufa a $37^{\circ} \mathrm{C}$ por 30 minutos.

Ao top ágar preparado previamente adicionou-se uma solução de histidina/biotina e homogeinizou-se. Transcorrido o tempo de incubação, foi adicionado aos tubos top ágar. Estes foram homogeinizados e vertidos nas placas de petri contendo o ágar mínimo glicosado. As placas foram incubadas por 48 horas a $37^{\circ} \mathrm{C}$. Após esse tempo foi realizada a contagem do número de colônias revertentes.

A avaliação mutagênica com sistema de ativação metabólica (+S9) foi realizada com fração microssômica S9 (S9 mix), preparada a partir do homogeinizado de fígado de ratos Sprague Dawley, previamente tratados com Aroclor 1254, adquiridos comercialmente na forma liofilizada. A adição de +S9 deve ser realizada antes da préincubação.

Após a contagem do número de revertentes foi calculada a razão de mutagenicidade (RM) para cada concentração utilizada. Os dados finais obtidos do ensaio foram analisados utilizando-se o programa estatístico Salanal (Salmonella Assay Analysis) versão 1.0 do Research Triangle Institute, RTP, Carolina do Norte, EUA. Tal programa permite avaliar o efeito dose-resposta por meio de cálculos de análise de variância (ANOVA- teste F) entre a medida do número de revertentes nas diferentes concentrações (doses) testadas e o controle negativo, seguido de uma regressão linear. O modelo do programa escolhido para análise dos dados foi o de Bernstein (BERNSTEIN et al, 1982). A inclinação da reta da parte linear da curva dose-resposta é também fornecida por esse programa e corresponde ao número de revertentes induzidos por unidade de medida da amostra analisada.

A partir dos resultados foi calculada a razão de mutagenicidade (RM) para cada dose analisada de cada composto. A RM é dada pela seguinte equação:

$\mathrm{RM}=\frac{\text { média } \mathrm{n} \text { - revertentes por placa teste (espontâneos }+ \text { induzidos) }}{\text { média } \mathrm{n}^{\mathrm{o}} \text { revertentes por placa do controle negativo (espontâneos) }}$

O crescimento espontâneo significa que o número de revertentes que desenvolveram na placa, independente de serem ou não induzidos, onde se considera como resposta positiva valores maiores ou iguais a dois (VALENT et al, 1993).

\section{RESULTADOS E DISCUSSÃO}

A avaliação da atividade mutagênica de novos fármacos é de fundamental relevância para a introdução na terapêutica de compostos mais seguros para uso humano. Ademais, a identificação do potencial mutagênico dos fármacos existentes nos submete à busca de novos compostos.

Há uma relação estreita entre mutagênese e a carcinogênese já que ambas apresentam alterações abruptas em uma única célula, permanentes e herdadas pelas células filhas. Por conta desta relação, recomendase a utilização de ensaios de mutagenicidade para a avaliação genotóxica de substâncias já existentes e de novos fármacos (MARON \& AMES, 1983; GÜIDO et al, 2001; FAGUNDES et al, 2005).

O teste de AMES é um dos preconizados pelas agências internacionais e instituições governamentais, com o objetivo de avaliar a capacidade mutagênica de drogas e compostos sintéticos. O teste de AMES caracteriza-se pela utilização de linhagens indicadoras de Salmonella typhimurium sensíveis às substâncias capazes de induzir diferentes tipos de mutação. Na presença de agentes mutagênicos, estas linhagens revertem o caráter de auxotrofia para a síntese de histidina e passam a formar colônias em meio desprovido deste aminoácido. Há aumento do número de colônias, que está diretamente relacionada a atividade mutagênica do composto. O teste também é realizado na presença e na ausência de ativação metabólica. Na ativação metabólica é utilizada fração microssômica S9 (S9 mix), preparada a partir do homogeneizado de fígado de ratos Sprague Dawley, previamente tratados com Arocloror 1254, adquiridos na forma liofilizada com objetivo de mimetizar parcialmente as condições de metabolização dos mamíferos (MARON \& AMES,1983; GÜIDO et al, 2001; SANTOS, 2007).

Entretanto, o metabólito mutagênico não é isolado, por isso não se conhece a estrutura química do metabólito genotóxico. Diversas outras metodologias têm sido descritas para avaliar a contribuição dos metabólicos na atividade farmacológica ou toxicológica dos compostos, entre estes métodos, destacam-se os modelos microbianos do metabolismo animal. Através deste pode-se isolar, identificar e avaliar a contribuição benéfica ou tóxica do processo metabólico (CARNEIRO et al, 2005).

De acordo com um estudo realizado pelo National Toxicology Program dos Estados Unidos, o teste fornece boa correlação com ensaios in vivo (UMBUZEIRO et al, 2004). 
Há diversas linhagens de Salmonella typhimurium modificadas geneticamente a fim de detectar um tipo predominante de mutação, entre elas podemos citar: TA 97, TA 98, TA 100 e TA 102. TA 100 e TA 102 detectam mutações que causam substituição de pares de base, TA 98 e TA 97 detectam alterações onde há defasagem no quadro de leituras do DNA (MARON \& AMES, 1983).

Dessa forma, avaliamos através das linhagens TA 100 e TA 102 a capacidade da talidomida em causar mutação que causa substituição de pares de base em Salmonella typhimurium (Tabela 1).

A ativação metabólica usando +S9 contém enzimas microssomais capazes de metabolizar a talidomida e permite indiretamente inferir a atividade mutagênica de seu(s) metabólito(s).

Tabela 1: Avaliação mutagênica da talidomida nas linhagens TA100 e TA102 de Salmonella typhimurium na presença e ausência de ativação metabólica (S9) representada pelo número médio de revertentes por placa, desvio padrão e razão de mutagenicidade.

\begin{tabular}{|c|c|c|c|c|c|}
\hline \multirow[t]{2}{*}{ composto } & \multirow[t]{2}{*}{ concentração } & \multicolumn{2}{|c|}{ TA100 } & \multicolumn{2}{|c|}{ TA102 } \\
\hline & & $+\mathrm{S} 9$ & -S9 & $+S 9$ & -S9 \\
\hline talidomida & $\begin{array}{l}0^{\mathrm{a}} \mu \mathrm{mol} / \text { placa } \\
0,0309 \\
0,155 \\
0,774 \\
3,87 \\
19,4\end{array}$ & $\begin{array}{l}103,7 \pm 7,4 \\
109,3 \pm 9(1,05) \\
121 \pm 35,3(1,16) \\
120,7 \pm 20(1,16) \\
104,3 \pm 8(1) \\
102,5 \pm 31(0,98) \\
592 \pm 6,3(5,7)^{b}\end{array}$ & $\begin{array}{l}139 \pm 9,5 \\
145,7 \pm 6,9(1,04) \\
148 \pm 9,1(1,06) \\
145 \pm 8,5(1,04) \\
131 \pm 4,9(0,94) \\
122 \pm 9,6(0,87) \\
1584+8,9(11,4)^{\mathrm{c}}\end{array}$ & $\begin{array}{l}323,3 \pm 10,02 \\
288,7 \pm 8,1(0,89) \\
253,7 \pm 37(0,78) \\
341,3 \pm 36(1,05) \\
258,5 \pm 0,8(0,8) \\
197 \pm 29,6(0,6) \\
1713+18,9(5,3)^{d}\end{array}$ & $\begin{array}{l}303,6 \pm 14,5 \\
330 \pm 17(1,09) \\
364 \pm 14,5(1,2) \\
357,8 \pm 21(1,17) \\
292 \pm 22(0,96) \\
230 \pm 55,6(0,75) \\
825 \pm 15,1(2,71)^{6}\end{array}$ \\
\hline
\end{tabular}

a) controle negativo: DMSO (100 $\mu \mathrm{L})$; b) 2-antramina: $1,25 \mu \mathrm{g} /$ placa $(50 \mu \mathrm{L})$; c) azida sódica: 1,25 $\mu \mathrm{g} /$ placa $(100 \mu \mathrm{L})$; d) 2-aminofluoreno: $1,25 \mu \mathrm{g} /$ placa $(50 \mu \mathrm{L})$; mitomicina: $0,5 \mu \mathrm{g} / \mathrm{placa}(100 \mu \mathrm{L})$.

Pelos resultados obtidos, observamos que a talidomida não apresentou atividade mutagênica no teste de AMES usando as linhagens TA100 e TA102.

A maior razão de mutagenicidade para TA 100 foi respectivamente de 1,16 utilizando ativação metabólica e 1,06 sem ativação metabólica na concentração de $0,155 \mu \mathrm{mol} / \mathrm{placa}(40 \mu \mathrm{g} / \mathrm{placa})$.

Para a linhagem TA102 a maior razão de mutagenicidade foi de 1,05 com ativação metabólica na concentração de $0,774 \mu \mathrm{mol} /$ placa $(200 \mu \mathrm{g} / \mathrm{placa})$ e de $1,17 \mathrm{sem}$ ativação metabólica na concentração de 0,774 $\mu \mathrm{mol} / \mathrm{placa}(40 \mu \mathrm{g} / \mathrm{placa})$.

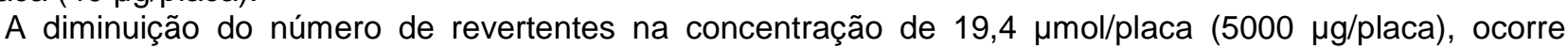
porque a alta concentração de talidomida causou toxicidade às células, levando a uma diminuição do número de revertentes. Além disso, as diferenças obtidas não foram significativas estatisticamente.

Estudos empregando o algoritmo CASE e MULTICASE também apontaram ausência de mutagenicidade da talidomida, embora alguns metabólitos contendo a subunidade hidroxilamina indicassem mutagenicidade. Entretanto, nenhum desses metabólitos foi identificado in vivo (ZHU et al, 1999).

Uma série de experimentos a fim de atestar a mutagenicidade e a carcinogenicidade da talidomida foi realizada por ASHBY et al (1997), porém os resultados obtidos são controversos, e estudos utilizando o teste de AMES demonstraram ausência de mutagenicidade nas linhagens TA98 e TA100, na presença e na ausência de ativação metabólica. Os resultados na TA100 estão em conformidade com os dados encontrados no presente trabalho. Além disso, avaliamos a talidomida na linhagem TA102 que detecta principalmente danos oxidativos. $\mathrm{O}$ mecanismo molecular da teratogênese da talidomida é obscuro e pouco conhecido. Sugere-se que os danos causados no DNA estão relacionados à formação de espécies radicalares (LIMA et al, 2001). Assim, através deste trabalho avaliou-se a talidomida em uma linhagem de Salmonella typhimurium (TA102) que fosse mais sensível à detecção de danos oxidativos. Entretanto, de acordo com os resultados obtidos, não foi possível observar mutagenicidade induzida pela talidomida na linhagem TA102.

\section{CONCLUSÕES}

Embora haja relatos na literatura evidenciando o potencial mutagênico deste fármaco em outros ensaios, esta atividade não pode ser observada pelo teste de AMES usando as linhagens TA100 e TA102. O entendimento das razões moleculares de ação mutagênica/carcinogênica da talidomida é de fundamental importância já que este fármaco ressurge como um novo agente bioativo a uma série de doenças, e permitirá o desenvolvimento de compostos mais seguros para utilização em humanos. 


\section{AGRADECIMENTOS}

O presente estudo foi financiado pela CAPES (Brasil).

\section{REFERÊNCIAS BIBLIOGRÁFICAS}

ASHBY, J.; et al. Thalidomide: lack of mutagenic activity across phyla and genetic endpoints. Mutation Research. v. 396, p. 45-64, 1997.

BERNSTEIN, L.; et al. An empirical approach to the statistical analysis of mutagenesis data from Salmonella test. Mutation Research. v. 97, p. 267-281, 1982.

CARNEIRO, E. O.; et al. Modelo microbiano do metabolismo animal: aplicação para o estudo do metabolismo do LASSBio 873. Revista Eletrônica de Farmácia. v. 2, n. 2, p. 44-47, 2005.

FAGUNDES, F. A.; et al. Annona coriacea induz efeito genotóxico em camundongos. Revista Eletrônica de Farmácia. v. 2, n.1, p. 24-29, 2005.

GÜIDO, R. V. C.; et al. Diminuição da atividade mutagênica do pró-fármaco NFOH-121 em relação ao nitrofural (nitrofurazona). Revista de Ciências Farmacêuticas. v. 22, n. 2, p. 319-333, 2001.

LIMA, L. M.; FRAGA, C. A. M.; BARREIRO, E. J. O renascimento de um fármaco: talidomida. Química Nova. v. 24, n. 5, p. 683-688, 2001.

MARON, D. M.; AMES, B. N. Revised methods for the Salmonella mutagenicity test. Mutation Research. v. 113, p.173-215, 1983.

MELCHERT, M.; LIST, A. The thalidomide saga. International Journal Biochemistry and Cell Biology. v. 39, p.1489-1499, 2007.

MIYACHI, H.; et al. Tumor necrosis factor-alpha production-inhibiting activity of phthalimide analogues on human leukemia THP-1 cells and a structure-activity relationship study. Bioorganic and Medicinal Chemistry. v. 5, n. 11, p. 2095-2102, 1997.

PALENCIA, G.; CALDERON, A.; SOTELO, J. Thalidomide inhibits pentylenetetrazole-induced seizures. Journal of the Neurological Sciences. v. 258, p.128-131, 2007.

SANTOS, J.L.. Planejamento, Síntese e Avaliação Farmacológica de Compostos Híbridos Potencialmente Ativos para o Tratamento da Anemia Falciforme. 2007.197p. Dissertação (Mestrado) Faculdade de Ciências Farmacêuticas, Universidade Estadual Paulista “Júlio de Mesquita Filho", Araraquara.

UMBUZEIRO, G. A.; et al. Teste de mutação reversa com Salmonella typhimurium [on line]. Disponível:http://www.sbmcta.org.br/?arq=doc01 [capturado em 23 julho 2007].

VALENT, G. U.; et al. Monitoring São Paulo state river in Brazil for mutagenic activity using the AMES test. Environmental Toxicology and Water Quality. v. 8, p. 371-381, 1993.

ZHU, X.; et al. Thalidomide and metabolites: indications of the absence of 'genotoxic' carcinogenic potencials. Mutation Research. v. 425, p.153-167, 1999.

isophorms were found in the protein source banana flour. Obtained results show that M. phaseolina is efficient in obtaining expression of amylases from alternative carbon sources. 